\title{
Asthma and pregnancy: a prospective study of 198 pregnancies
}

\author{
B STENIUS-AARNIALA, P PIIRILÄ, K TERAMO
}

From the Department of Pulmonary Medicine, Helsinki University Central Hospital, and the First and Second Departments of Obstetrics and Gynaecology, University Central Hospital, Helsinki, Finland

ABSTRACT A study was designed to investigate whether asthma, when carefully managed, is $\underset{-}{\omega}$ associated with an increased risk of complications in connection with pregnancy. One hundred and $\overrightarrow{\mathrm{N}}$ eighty one asthmatic women were monitored during 198 pregnancies. Antiasthmatic treatment $ᄋ$ consisted of inhaled $\beta_{2}$ adrenergic drugs, beclomethasone, sodium cromoglycate, oral theophylline, and systemic corticosteroids as needed. Postpartum information on asthmatic symptoms and infant feeding was collected by means of a questionnaire. A control group of 198 non-asthmatic pregnant women was matched for age and parity. Atopic women had less severe asthma than non-atopic women. During pregnancy $40 \%$ of the patients were managed with the same antiasthmatic $\vec{\bullet}$ medication as before pregnancy; $18 \%$ needed less and $42 \%$ more medication. Pre-eclampsia occurred $\infty_{\infty}^{\infty}$ more often in asthmatic than control subjects, especially in patients with severe asthma. Hypoglycaemia occurred more often in infants of mothers with severe asthma than in infants of mothers with less severe disease. Theophylline medication at term did not influence labour or delivery. Asthma caused no emergencies during labour. Among the asthmatic subjects $28 \%$ of babies were delivered by caesarean section compared with $17 \%$ in the control group. There was no difference $\frac{\Phi}{\varnothing}$ between asthmatic and control subjects with regard to length of gestation, birth weight, incidence of $\overrightarrow{\overrightarrow{0}}$ perinatal deaths, low Apgar scores, neonatal respiratory difficulties, hyperbilirubinaemia, or 3 malformations. It is concluded that severe asthma or systemic corticosteroid treatment (or both) $\supsetneq$ during pregnancy seems to increase the incidence of mild pre-eclampsia in the mother and hypoglycaemia in the infant. The findings suggest that careful supervision of asthma during pregnancy and labour by obstetricians and chest physicians working in close collaboration should prevent most of the serious obstetric and neonatal complications of asthma in pregnancy reported by previous authors.

Gluck and Gluck,' after a prospective study, reported that symptoms of asthma worsened during pregnancy in $43 \%$ of patients and improved in $14 \%$. Exacerbation of asthmatic symptoms usually occurs during the last trimester, ${ }^{\prime}$ although women with extrinsic (atopic) asthma tend to have fewer symptoms during pregnancy than patients with intrinsic asthma. ${ }^{2}$ Bronchial asthma in the mother has been associated with increased perinatal morbidity and mortality, ${ }^{34}$ and also with increased morbidity during infancy. ${ }^{3}$ Obstetric complications have been observed more

Address for reprint requests: Associate Professor B S M SteniusAarniala, Department of Pulmonary Medicine, Helsinki University Central Hospital, 00290 Helsinki, Finland.

Accepted 21 September 1987 often in asthmatic than in control subjects, ${ }^{3}$ though it is uncertain whether the complications connected with pregnancy are due to the asthma itself or to the drugs $\frac{7}{0}$ used to treat it.

Because most pharmaceutical companies place $\tilde{\sigma}$ restrictions or cautions against the use of drugs during $\mathrm{N}$ pregnancy, many physicians advise their patients to $N$ avoid or decrease their medication. There seems to be ${ }^{\omega}$ no argument, however, against the use of most antiasthmatic drugs during pregnancy. ${ }^{5-8}$

To investigate the effect of asthma on pregnancy further we performed a prospective four year study on ${ }^{+}$ the outcome of pregnancy in asthmatic patients. Our aim was to give the optimum treatment for the asthma $\overrightarrow{\mathbb{D}}$ so far as possible and to monitor carefully the progress $\frac{\mathcal{D}}{\mathbb{Q}}$ of the pregnancy and the condition of the fetus and the $\mathrm{a}$ newborn infant. 


\section{Methods}

\section{THE SUBJECTS}

We followed 198 pregnancies lasting 24 weeks or more in 181 women with asthma. The patients were seen in the departments of pulmonary medicine and of obstetrics and gynaecology at the University Central Hospital of Helsinki during 1978-82.

A control group of 198 non-asthmatic women were collected retrospectively from the labour records. The control subjects were matched for age ( \pm 2 years), parity (primipara or multipara), and time of delivery (the closest possible date after that of the reference case). Relative birth weights (SD units) were calculated separately for girls and boys on the basis of a Finnish reference population.

Seventeen patients had two pregnancies during the investigation period. Two pairs of twins were born to the mothers with asthma and one pair to the mothers in the control group. Thus the total number of newborn infants was 200 in the study group and 199 in the control group.

Clinical data on the patients are shown in table 1 . Patients were referred to us by maternity centres or physicians in out patient practice. Twenty per cent of the patients were admitted to the study during the first trimester of pregnancy, $54 \%$ during the second, and $26 \%$ during the third. All patients satisfied the criteria of asthma set by the American Thoracic Society and

Table 1 Clinical data for asthmatic and control subjects

\begin{tabular}{lll}
\hline & Asthma & Control \\
\hline No of mothers & 182 & 198 \\
No of pregnancies & 198 & 198 \\
No of primiparae & 112 & 112 \\
Age (y): Mean & $28 \cdot 9$ & $28 \cdot 3$ \\
$\quad$ Range & $17-43$ & $19-41$ \\
No who $(\mathrm{n})$ & 22 & 13 \\
$\begin{array}{l}\text { during pregnancy } \\
\text { No of newborn infants }\end{array}$ & $16^{*}$ & $32^{*}$ \\
\hline
\end{tabular}

${ }^{*} \mathrm{p}<0.05$. the American College of Chest Physicians in 1975.9

Patients were divided into four severity groups on the basis of the treatment necessary to control asthma during pregnancy and the occurrence of acute exacerbations (table 2). An exacerbation was defined as an acute worsening of the asthma that needed medical attention outside scheduled appointments. A slow deterioration as judged by history and regular peak flow measurements during scheduled appointments was not considered an exacerbation. On the basis of skinprick tests or specific serum IgE levels (RAST), the women were classified as atopic $(62 \%)$ or non-atopic $(38 \%)$. In $69 \%$ the onset of asthma had occurred before the age of 16 years. Blood pressure was measured at each antenatal visit. For a diagnosis of pre-eclampsia, a previously normotensive patient had to have a diastolic blood pressure of $90 \mathrm{~mm} \mathrm{Hg}$ or more on at least two occasions during the third trimester. Premature rupture of membranes was defined as the efflux of amniotic fluid 24 hours or more before the beginning of labour. Cholestasis of pregnancy was diagnosed if serum concentrations of aminotransferase (ASAT or ALAT) or bile acids were raised. ${ }^{10}$

There were significantly $(p<0.01)$ more primiparae in group I $(80 \%)$ than in groups II, III, and IV, where the percentages were 50,52 , and 47 respectively.

\section{THE INFANTS}

The condition of newborn infants was evaluated by the Apgar score at one and five minutes. Neonatal hypoglycaemia was defined as significant if two or more whole blood glucose values were below 1.8 $\mathrm{mmol} / 1(32.4 \mathrm{mg} / 100 \mathrm{ml})$ and at least one of them was obtained after the age of 6 hours. Hyperbilirubinaemia was diagnosed if the serum bilirubin level exceeded $255 \mu \mathrm{mol} / 1(14.9 \mathrm{mg} / 100 \mathrm{ml})$ or if phototherapy or exchange tranfusion was necessary. Perinatal deaths included still births of fetuses weighing $500 \mathrm{~g}$ or more and neonatal deaths during the first week of life.

Table 2 Severity of asthma in 198 pregnancies and use of systemic (oral or intravenous) corticosteroid treatment (SCT)

\begin{tabular}{|c|c|c|c|c|c|c|}
\hline Group & $\begin{array}{l}\text { Antiasthmatic } \\
\text { treatment } \\
\text { during } \\
\text { pregnancy* }\end{array}$ & $\begin{array}{l}\text { Exacerbations } \\
\text { of asthma } \\
\text { during } \\
\text { pregnancy }\end{array}$ & $\begin{array}{l}\text { Hospital } \\
\text { admission } \\
\text { because of } \\
\text { asthma during } \\
\text { pregnancy }\end{array}$ & No $(\%)$ & $\begin{array}{l}\text { Daily } \\
\text { maintenance } \\
S C T \\
\geqslant 2 \text { months } \\
\text { (No of cases) }\end{array}$ & $\begin{array}{l}\text { Short courses } \\
\text { of } S C T \\
\text { (No (\%) } \\
\text { of cases) }\end{array}$ \\
\hline I-very mild & $\begin{array}{l}\text { None or inhaled } \\
\text { bronchodilator, } \\
\text { sodium } \\
\text { cromoglycate or } \\
\text { beclomethasone }\end{array}$ & None & - & $56(29)$ & - & - \\
\hline II-mild & $\begin{array}{l}\text { As above } \\
\text { plus oral } \\
\text { bronchodilator }\end{array}$ & None & - & $52(27)$ & - & 一 \\
\hline $\begin{array}{l}\text { III-moderately } \\
\text { severe }\end{array}$ & As in group II & One or more & - & $56(28)$ & 2 & $28(50)$ \\
\hline IV-severe & As in group II & One or more & Once or more & $34(17)$ & 7 & $30(88)$ \\
\hline
\end{tabular}

*Systemic corticosteroids excluded. 
Six months after the delivery a questionnaire was sent out to the asthmatic women to collect detailed information on infant feeding and the course and medication of the asthma during the postpartum period. Those mothers who still breast fed at the time completed the information later.

DIAGNOSTIC PROCEDURES, FOLLOW UP, ND TREATMENT

Clinical evaluation of asthma was done at least at first attendance and during the last month of pregnancy, but more frequently if warranted. The evaluation was based on the clinical picture, the need for medication, daily monitoring of peak expiratory flow, and dynamic spirometry. Patients were told to contact us at once if symptoms increased. Lung function measurements were not done in patients with threatened premature labour.

For comparison of medication during pregnancy with medication before or after pregnancy, a substantial increase in maintenance treatment, such as the addition of a new antiasthmatic drug, was counted, but not small dose adjustments or transient intensification of treatment for acute exacerbations.

Medication was intensified if the patient had disturbed sleep because of asthma, decreased exercise tolerance, or diurnal variation in peak expiratory flow of around $30 \%$ or more over several consecutive days, or if the FEV , measured at rest in daytime with full medication showed a $20 \%$ or more reversibility. Beta agonists, ipratropium bromide, beclomethasone (maximum dose $400 \mu \mathrm{g} / \mathrm{a}$ day), and sodium cromoglycate could be inhaled during pregnancy and lactation and methylxanthines taken by mouth. During the period of study steroids for high dose inhalation were not available in Finland. Systemic corticosteroids were given as required (table 2), usually an initial dose of $24 \mathrm{mg}$ of methylprednisolone followed by reducing doses for 6-12 days.

Acute exacerbations of asthma were treated conventionally with intravenous theophylline and methylprednisolone and high doses of inhaled $\beta_{2}$ sympathomimetics and ipratropium bromide.

Antihistamines, phenylephrine or phenylpropanolamine, and topical medication for relief of nasal symptoms were allowed occasionally during the second and third trimesters only. Systemic ephedrine and epinephrine were avoided.

Patients were seen at the out patient maternity clinic once a month during the first and second trimesters and every one to four weeks after 28 weeks. Obstetric and ultrasonic examinations were performed to determine gestational age, number of fetuses, fetal morphology and to monitor intrauterine growth. Fetal well being was monitored in the last trimester by non-stressed fetal heart rate testing. The infants were examined physically by neonatologists at least three times - at birth, at the age of 1 day, and on discharge from hospital at the age of at least 7 days.

The $\chi^{2}$ test (two tail), Fisher's exact test, Student's paired $t$ test, and one way analysis of variance (ANOVA) were used for statistical comparisons.

\section{Results}

\section{COURSE OF ASTHMA DURING PREGNANCY AND} POSTPARTUM

More than half of the atopic subjects (59\%) belonged to groups I and II (very mild or mild asthma), whereas most of the non-atopic subjects $(59 \%)$ belonged to groups III and IV (moderately severe or severe asthma). The difference is significant $(p<0.05)$. Forty per cent of the patients managed with the same maintenance medication as before pregnancy, whereas $42 \%$ needed more and $18 \%$ less medication than before. There was no difference between atopic and non-atopic women in this respect. Further data depicting the course of asthma during pregnancy in atopic and non-atopic patients are shown in table 3. Patients in group IV had significantly lower values for FEV and for maximum flow at $50 \%$ vital capacity $\left(\mathrm{Vmax}_{50}\right)$ during the last month of pregnancy, although these tests were done in a clinically stable phase of the asthma (table 4).

Asthmatic symptoms during labour were mild and easily controlled by means of a self administered $\beta_{2}$ agonist from a metered dose inhalation device. None of the patients needed intensive antiasthmatic treatment during labour.

Ninety one per cent of the mothers returned the postpartum questionnaire. About half of the infants were breast fed for six months or more. The corresponding figure for the control group is not available. There was no difference in the length of breast feeding between the severity groups.

According to the questionnaire, $26 \%$ of the patients thought that their asthma deteriorated after delivery, whereas $34.5 \%$ stated that they felt better. There was no difference between atopic and non-atopic patients

Table 3 Course of asthma during pregnancy in patients with atopic and non-atopic asthma

\begin{tabular}{lll}
\hline & \multicolumn{2}{l}{ Type of asthma } \\
\cline { 2 - 3 } & $\begin{array}{l}\text { Atopic } \\
(n=123) \\
(\%)\end{array}$ & $\begin{array}{l}\text { Non-atopic } \\
\left(\begin{array}{l}n=75) \\
(\%)\end{array}\right.\end{array}$ \\
\hline $\begin{array}{l}\text { Exacerbations during } \\
\text { pregnancy }\end{array}$ & 38 & 47 \\
$\begin{array}{l}\text { Treatment with systemic } \\
\text { corticosteroids }\end{array}$ & 25 & $35 \cdot 5$ \\
$\begin{array}{l}\text { Hospital admission } \\
\text { Symptoms during labour }\end{array}$ & $13^{*}$ & $22^{*}$ \\
\hline *p $<0.05$ & 14 & 22 \\
\hline
\end{tabular}

\begin{tabular}{lll}
\hline & \multicolumn{2}{l}{ Type of asthma } \\
\cline { 2 - 3 } & $\begin{array}{l}\text { Atopic } \\
(n=123) \\
(\%)\end{array}$ & $\begin{array}{l}\text { Non-atopic } \\
\left(\begin{array}{l}n=75) \\
(\%)\end{array}\right.\end{array}$ \\
\hline $\begin{array}{l}\text { Exacerbations during } \\
\text { pregnancy }\end{array}$ & 38 & 47 \\
$\begin{array}{l}\text { Treatment with systemic } \\
\text { corticosteroids }\end{array}$ & 25 & $35 \cdot 5$ \\
$\begin{array}{l}\text { Hospital admission } \\
\text { Symptoms during labour }\end{array}$ & $13^{*}$ & $22^{*}$ \\
\hline *p $<0.05$ & 14 & 22 \\
\hline
\end{tabular}
(

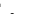
N 
Table 4 Forced vital capacity ( FVC), forced expiratory volume in one second $\left(F E V_{1}\right)$, and maximal expiratory flow at $50 \%$ of vital capacity $\left.\left(\dot{V}_{\max }\right)_{50}\right)$ at 36-40 weeks of pregnancy (values are means with standard deviations in parentheses)

\begin{tabular}{|c|c|c|c|c|}
\hline & \multicolumn{4}{|c|}{ Severity group } \\
\hline & $I$ & II & $I I I$ & $I V$ \\
\hline 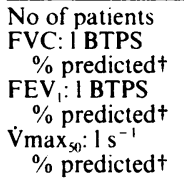 & $\begin{array}{c}52.56 \\
4 \cdot 0(0 \cdot 6) \\
100(13) \\
3 \cdot 3(0 \cdot 5) \\
96(14) \\
4 \cdot 2(1 \cdot 0) \\
83(21)\end{array}$ & $\begin{array}{c}52 \cdot 52 \\
4 \cdot 1(0 \cdot 5) \\
101(11) \\
3 \cdot 3(0 \cdot 4) \\
95(12) \\
4 \cdot 0(1 \cdot 0) \\
80(20)\end{array}$ & $\begin{array}{c}49.56 \\
4 \cdot 0(0 \cdot 6) \\
100(13) \\
3.0(0 \cdot 7) \\
89(19) \\
3 \cdot 5(1 \cdot 0) \\
71(21)\end{array}$ & $\begin{array}{c}29 \cdot 34 \\
4 \cdot 0(0 \cdot 6) \\
97(15) \\
3 \cdot 0(0 \cdot 7) \\
86(20)^{*} \\
3 \cdot 2(1 \cdot 4) \\
63(29)^{* *}\end{array}$ \\
\hline
\end{tabular}

$* * \mathrm{p}<0.001$ (ANOVA)

tSee reference 24 .

in this respect. Nineteen out of 34 patients $(56 \%)$ in group IV had fewer asthma symptoms after delivery, whereas improvement occurred in only 12 of 55 patients $(22 \%)$ in group I $(p<0.001)$. Fifty eight per cent of the asthmatic mothers breast fed for six months or more. Symptoms did not change significantly after the cessation of breast feeding in any group.

\section{COMPLICATIONS DURING PREGNANCY AND \\ LABOUR}

There was no difference between asthmatic and control subjects with regard to the length of gestation.

There were no cases of eclampsia. Pre-eclampsia was observed significantly $(p<0.001)$ more often in the asthmatic than in the control group $(14.6 \% v$ $4.5 \%$ ) (table 5 ). The incidence of mild pre-eclampsia was three times higher $(29 \%)$ in group IV $(p<0.05)$ than in group I (patients with mild asthma-8.7\%).

Table 5 Complications of 198 pregnancies in asthmatic women and 198 pregnancies in matched control women

\begin{tabular}{lll}
\hline & \multicolumn{2}{l}{ No of complications } \\
\cline { 2 - 3 } Diagnosis & Asthmatic & Control \\
\hline Pre-eclampsia & $28^{*}$ & 9 \\
Recurrent intrahepatic cholestasis & & \\
of pregnancy & 3 & 3 \\
Gestational diabetes & 4 & 5 \\
Insulin treated diabetes & 1 & 3 \\
Neurological diseases & 2 & 1 \\
Hypertension & 2 & 2 \\
Ulcerative colitis & 2 & 1 \\
Transient eosinophilic infiltrates & $2 * *$ & 0 \\
$\quad$ (Loeffler's syndrome) & 0 & 1 \\
Sarcoidosis & 5 & 1 \\
Urinary tract infection & 3 & 1 \\
Sinusitis or otitis media & 0 & 2 \\
Genital herpes & 1 & 0 \\
Sepsis & 0 & 1 \\
Appendicitis & 2 & 1 \\
Uterine haemorrhage & 3 & 1 \\
Ablatio placentae & 5 & 10 \\
Premature rupture of membranes & 5 & \\
\hline
\end{tabular}

${ }^{*} \mathrm{p}<0.001$.

**Two pregnancies in the same patient.
Proteinuria was more frequent in asthmatic (4\%) than control subjects $(2 \%)$ and in groups III and IV $(6 \%)$ than in groups I and II (3\%), though the differences were not significant. Pre-eclampsia occurred significantly more frequently $(25 \%, \mathrm{p}<0.01)$ in patients who had received systemic steroids at some time than in those who had not $(10 \%)$. The incidence of maternal complications other than pre-eclampsia was no higher in asthmatic than in control women (table 5).

\section{MODE OF DELIVERY}

The incidence of interventions in the form of induction or enhancement of labour was no greater in asthmatic than in control women, nor was there any difference between severity groups.

Caesarean sections were performed more frequently in the asthmatic than in the control women (table 6). Severe asthma was the main indication in eight of the 26 patients having elective caesarean sections, seven of them belonging to group IV. The operation was carried out when the asthma was adequately controlled. In no instance was severe, acute asthma the direct reason for a caesarean section. Emergency caesarean sections occurred with equal frequency and were performed for similar reasons in asthmatic and control subjects.

Prolongation of the third phase of delivery $(\geqslant 15$ $\mathrm{min})$ and haemorrhage $(\geqslant 1000 \mathrm{ml})$ occurred more

Table 6 Numbers of obstetric interventions in 198 pregnancies of 181 asthmatic and 198 control subjects

\begin{tabular}{lll}
\hline & Asthmatic & Control \\
\hline Induced labour* & $60 / 172$ & $58 / 186$ \\
Enhancement of labour by & 90172 & $109 / 186$ \\
$\quad$ oxytocin & $55^{* *}$ & $34^{* *}$ \\
Caesarean section: Total & $26^{* *}$ & $12^{* *}$ \\
$\quad$ Elective & 10 & 14 \\
Vacuum extraction & 8 & 9 \\
Vaginal delivery for & & \\
breech presentation & \\
\hline *Elective caesarean sections excluded. & \\
$* *$ p $<0 \cdot 05$ &
\end{tabular}


Table 7 Clinical characteristics of newborn infants of asthmatic and control women (numbers with percentages in square brackets unless otherwise specified)

\begin{tabular}{|c|c|c|c|}
\hline & \multicolumn{2}{|c|}{ Asthmatic patients } & \multirow[b]{2}{*}{ Controls } \\
\hline & $\begin{array}{l}\text { Groups } \\
I-I I\end{array}$ & $\begin{array}{l}\text { Groups } \\
I I I-I V\end{array}$ & \\
\hline No of infants & 109 & 91 & 199 \\
\hline $\begin{array}{l}\text { Gestational age } \\
\text { (days, mean (SD)) }\end{array}$ & $278(14)$ & $272(17)$ & $276(21 \cdot 6)$ \\
\hline $\begin{array}{l}\text { Birthweight } \\
\text { (g, mean (SD)) }\end{array}$ & $3479(587)$ & $3418(760)$ & $3483 \cdot 5(559 \cdot 5)$ \\
\hline (SD units, mean (SD)) & $-0.13(0.61)$ & $-0.07(0.92)$ & $-0 \cdot 17(0 \cdot 73)$ \\
\hline Hypoglycaemia (No $(\%)$ ) & $\quad 1[1]$ & $7[8]^{*}$ & $11[6]$ \\
\hline Hyperbilirubinaemia & $7[6]$ & $8[9]$ & $17[9]$ \\
\hline Agar score $\leqslant 6$ at $1 \mathrm{~min}$ & $3[3]$ & $4[4]$ & $7[4]$ \\
\hline Respiratory difficulty & 0 & $4[4]$ & $4[2]$ \\
\hline Perinatal deaths & $1[1]$ & $1[1]$ & $1[0 \cdot 5]$ \\
\hline $\begin{array}{l}\text { Transferred to the } \\
\text { newborn intensive } \\
\text { care unit }\end{array}$ & $5[5]$ & $8[8]$ & 14[7] \\
\hline
\end{tabular}

often among patients who had received theophylline by mouth at the time of delivery than among those who had not been given theophylline or among control subjects, though the differences were not significant. The severity of asthma had less influence on these measures than theophylline medication.

PERINATAL OUTCOME

The birth weight of the child did not differ between asthmatic and control groups (table 7) and was not affected by the severity of asthma.

The incidence of perinatal death, low Apgar scores, respiratory difficulties, hyperbilirubinaemia, and malformations was no higher among the infants of asthmatic mothers than among the control infants. A low Apgar score in the infant was not related to exacerbations of asthma in the mother.

Hypoglycaemia in the newborn infants was no more common in the asthmatic than in the control groups but it occurred more frequently $(p<0.05)$ in groups III and IV than in groups I and II. There was, however, no significant relation between hypoglycaemia of the infant and pre-eclampsia in the mother.

\section{Discussion}

In Finland labour and deliveries take place in municipal or university hospitals -in our district $40 \%$ in the latter. The common practice is to refer complicated cases to the university hospital, so we assume that our sample represents at least $40 \%$ of all asthmatic women giving birth in our district during the four years of the study. Patients with severe or troublesome asthma or with difficulties in tolerating treatment may be overrepresented because they may have been more readily referred than patients with mild or stable disease.

Our findings do not agree with previously reported observations that asthma or atopic disease in the mother is associated with prematurity, ${ }^{3411}$ perinatal death, ${ }^{3}$ low Apgar score, ${ }^{3}$ respiratory difficulties, ${ }^{3}$ hyperbilirubinaemia, ${ }^{12}$ or low birth weight.$^{341113}$ In earlier reports complications are probably attributable to the disease itself, as antiasthmatic treatment was less efficient at the time. Thus asthmatic patients were considered to be high risk patients, resulting in some instances in premature induction of labour. Since our aim was to maintain patients as symptom free as possible, none of our patients had severe bronchial obstruction continuously throughout pregnancy. Moreover, ephedrine was probably used in the patients in earlier studies, whereas it was avoided in our series. Ephedrine may lessen uterine blood flow ${ }^{14}$ and thus decrease the birth weight.

Reports on the adverse effects of corticosteroid treatment during pregnancy are contradictory. Apgar ${ }^{15}$ reported an increased incidence of cleft palate in two series of pregnancies in women treated with systemic corticosteroids in early pregnancy. The incidence of stillbirths was eight times higher in women having continuous steroid treatment than in a corresponding group of untreated women with the same diseases. ${ }^{16}$ The alarming findings in these studies may in part be the result of severe underlying disease rather than the treatment. Two studies of pregnant asthmatic women, some having short term and some long term systemic corticosteroids, showed no complications attributable to steroid treatment. ${ }^{17}$ An association between asthma and pre-eclampsia of pregnancy has been reported. ${ }^{4}$ We confirmed this, but the fact that blood pressure was measured slightly more frequently in the women with asthma (16 times on average) than in controls (14 times) might have contributed to our results. The cases of pre-eclampsia in our study were mild. Only a few patients had albuminuria, and there were no cases of eclampsia. In our study the incidence of pre-eclampsia in the mother and hypoglycaemia in the newborn were higher in the groups with more severe asthma, groups III and IV. These groups, however, contain the patients who had occasional or continuous systemic steroids during pregnancy, making it difficult to separate the influence of systemic corticosteroids from that of severe asthma. In a study ${ }^{19}$ on the outcome of pregnancy in women requiring systemic corticosteroids, the complications were attributed to acute exacerbations of asthma rather than to corticosteroid treatment. Although the direct effects of systemic steroids on the fetus appear to be small, their indirect effects will still form a risk for the infant. Since, however, an acute exacerbation of asthma carries even greater risks for both mother and child, systemic steroids should not be withheld when 
necessary.

Dombrowski and coworkers ${ }^{20}$ reported a lower incidence of pre-eclampsia in asthmatic patients having theophylline treatment than in patients not so treated. We could not confirm this finding. Possibly the asthma of the patients not having theophylline in Dombowski's study ${ }^{20}$ was less well controlled, contributing to the increased incidence of pre-eclampsia. In our study theophylline treatment during the last weeks of pregnancy was not associated with signs of uterine atony, though the theophylline doses given were rather low and sustained release preparations were not in use at the time of the study. Higher serum theophylline concentrations in the mother might be associated with complications of labour and delivery. With the new topical steroids inhaled in doses from 400 to $1600 \mu \mathrm{g}$ daily that we now use during pregnancy, systemic antiasthmatic treatment can often be avoided altogether. When theophylline treatment is necessary the dosage is carefully adjusted to keep serum concentrations as low as possible.

Our study shows virtually the same percentages as earlier reports on improvement or deterioration of asthma during pregnancy, ${ }^{1}$ although Sims et $a l^{13}$ did not find any fluctuations attributable to pregnancy in serially performed lung function tests in 27 patients. According to Schatz et al, ${ }^{21}$ women tend to follow the same pattern during all pregnancies with respect to the course of their asthma. In the 13 women in our series followed during more than one pregnancy medication was checked and adjusted at an earlier stage and the asthma better controlled during the second pregnancy.

There was a higher incidence of caesarean sections in our asthmatic patients than in the control group. One explanation for this could be that pregnant asthmatic patients have been considered to be high risk patients, and so operative interventions have been used more readily than in healthy pregnant women. Severe asthma was the reason for the operation in only a few cases, and in no case was caesarean section performed because of an acute exacerbation of asthma.

Antiasthmatic drugs may pass into breast milk, and mothers have therefore been advised not to breast feed. We have, however, found no evidence in published reports that inhaled drugs or moderate doses of theophylline or systemic steroids taken by mouth by the lactating mother would be harmful to the infant. ${ }^{22} 23$ Breast feeding was encouraged in our patients and the incidence and duration of breast feeding among the asthmatic mothers in our series were similar to those among Finnish mothers in general.

The outcome of pregnancy was not significantly affected by the asthma in the mother and earlier findings relating to asthma as a risk factor in preg- nancy were not confirmed. The findings of our study support the theory that with adequate treatment and surveillance of the asthmatic patient during pregnancy and delivery complications can be largely avoided.

\section{References}

1 Gluck JC, Gluck PA. The effects of pregnancy on asthma: a prospective study. Ann Allergy 1976;37: 164-8.

2 Hiddlestone $\mathrm{HJ}$. Bronchial asthma and pregnancy. $N Z$ Med J 1964;63:521-3.

3 Gordon M, Niswander KR, Berendes H, Kantor AG. Fetal morbidity following potentially anoxigenic obstetric conditions. VII. Bronchial asthma. Am J Obstet Gynec 1970;106:421-9.

4 Bahna SL, Bjerkedahl T. The course and outcome of pregnancy in women with bronchial asthma. Acta Allergol 1972;27:397-406.

5 Heinonen OP, Slone D, Shapiro S. Birth defects and drugs in pregnancy. Littleton, Montana: Publishing Science Group, 1977.

6 Spector SL. The treatment of the asthmatic mother during pregnancy and lactation. Ann Allergy 1983; 51:173-7.

7 Greenberger PA, Patterson R. Beclomethasone diproprionate for severe asthma during pregnancy. Ann Intern Med 1983;98:478-80.

8 Stenius-Aarniala B, Teramo K. Asthma and pregnancy. In: Settipane GA, ed. Current treatment of ambulatory asthma. New England and Regional Allergy Proceedings: Rhode Island, 1986.

9 Pulmonary terms and symbols. A report of the ACCPATS Joint Committee on Pulmonary Nomenclature. Chest 1975;67:583-92.

10 Laatikainen T, Ikonen E. Serum bile acids in cholestasis of pregnancy. Obstet Gynec 1977;50:313-8.

11 Hunter JR, Nell PA, Turner BA. Atopy other than asthma is a high-risk factor in pregnancy [abstract]. $J$ Allergy Clin Immunol 1986;77 (suppl):162.

12 Light WC, Wortley G. Effect of maternal asthma on the newborn. J Allergy Clin Immunol 1980;65:204.

13 Sims CD, Chamberlain GVP, de Swiet M. Lung function tests in bronchial asthma during and after pregnancy. Br J Obstet Gynaec 1976;83:434-7.

14 Ralston DH, Shnider SM, deLorimier AA. Effects of equipotent ephedrine, metaraminol, mephentermine, and methoxamine on uterine blood blow in the pregnant ewe. Anesthesiology 1974;40:354.

15 Apgar V. The drug problem in pregnancy. Clin Obstet Gynec 1966;9:623-30.

16 Warrell DW, Taylor R. Outcome for the fetus of mothers receiving prednisolone during pregnancy. Lancet 1968 ; i:117-8.

17 Walsh SD, Clark FR. Pregnancy in patients on long-term corticosteroid therapy. Scot Med J 1967;12:302-6.

18 Schatz M, Patterson R, Zitz S, O'Rourke J, Melam H. Corticosteroid therapy for the pregnant asthmatic patient. JAMA 1975;233:804-7. 
19 Fitzsimons R, Greenberger PA, Patterson R. Outcome of pregnancy in women requiring corticosteroids for severe asthma. J Allergy Clin Immunol 1986;78:349-53.

20 Dombrowski MP, Bottoms SF, Boike GM, Wald J. Incidence of preeclampsia among asthmatic patients lower with theophylline. Am J Obstet Gynecol 1986; 155:265-7.

21 Schatz M, Harden K, Forsythe A, Chilingar L, Hoffman C, Sperling W, Zeiger RS. Course of asthma post-partum (PP) and during successive pregnancies: a prospective analysis [abstract]. $J$ Allergy Clin Immunol $\overrightarrow{\vec{\omega}}$ 1986;77 (suppl):161.

22 Chung KF, Barnes PJ. Prescribing in pregnancy. Treatment of asthma. Br Med J 1987;294:103-5.

23 Hüter J. Ubergang von Medikamenten in die Muttermilch und Nebenwirkungen beim gestillten Kind. Stuttgart: Georg Thieme Verlag, 1970.

24 Viljanen AA, Halttunen PK, Kreus K-E, Viljanen BC. Spirometric studies in non-smoking, healthy adults. Scand J Clin Lab Invest 1982;42 (suppl 159):5-20. 